DOI 10. 18307/2020. 0123

(c) 2020 by Journal of Lake Sciences

\title{
柴达木盆地西北缘昆特依凹陷的双层钾盐成矿模式特征及成因"
}

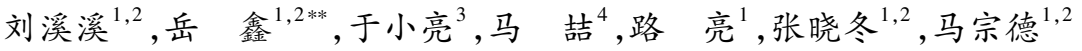 \\ (1: 青海省柴达木综合地质矿产勘查院,格尔木 816000$)$ \\ (2: 青海省柴达木盆地盐湖资源勘探研究重点实验室,格尔木 816000$)$ \\ (3: 青海省地质调查局, 西宁 810000 ) \\ (4: 青海省盐湖地质与环境重点实验室,西宁 810000)
}

摘 要: 柴达木盆地是我国和世界重要的钾盐产地, 目前对地表浅层盐湖钾盐研究颇多,但对深部碎屑孔隙钾盐研究较 少. 本文以昆特依凹陷为例, 总结柴达木盆地钾盐成矿的时空变化规律, 通过对该区地质、水文、古环境及卤水储层特征 等分析建立 “双层钾盐” 成矿模式: 上层为赋存在 $Q_{\mathrm{p} 2-\mathrm{h}}$ 盐湖相化学盐类晶体裂隙间的晶间卤水,下层是 $Q_{\mathrm{p} 1}$ 冲洪积相砂砾 孔隙卤水. 采用聚类分析、特征系数、介稳相图、piper 三线图及氢氧同位素等数理、地球化学手段分析上、下层卤水离子含 量, 探讨 “双层钾盐” 模式成因和上、下层卤水的内在联系. 研究认为, 昆特依凹陷内 “双层钾盐” 赋存卤水均为陆相沉积 环境中的盐岩溶滤水, 其中上层晶间卤水更多表现为盐岩溶解, 但也不乏溶滤作用, 下层砂砾孔隙卤水则着重表现为石 盐的溶解; 上层晶间卤水表现出下层砂砾孔隙卤水深度演化的特征, 下层砂砾孔隙卤水具有对深部古盐岩层及上层晶间 层的继承性;昆特依凹陷周边的新近纪背斜构造区油田水在成因上也与“双层钾盐”卤水密切相关.

关键词: 柴达木盆地;钾盐矿床;晶间卤水;砂砾孔隙卤水;水化学特征;昆特依凹陷

\section{Characteristics and genesis of the double potash layer metallogenetic model of Kunteyi Depression in the northwest margin of Qaidam Basin*}

\author{
LIU Xixi ${ }^{1,2}$, YUE Xin ${ }^{1,2 * *}$, YU Xiaoliang ${ }^{3}$, MA Zhe ${ }^{4}$, LU Liang $^{1}$, ZHANG Xiaodong $^{1,2}$ \& MA Zongde ${ }^{1,2}$ \\ (1: Qaidam Integrated Geological Exploration Institute of Qinghai Province, Golmud 816000, P.R.China) \\ (2: Key Laboratory of Salt Lake Resources Exploration in Qaidam Basin, Qinghai Province, Golmud 816000, P.R.China) \\ (3: Geology Survey Bureau of Qinghai Province, Xining 810000, P.R. China) \\ (4: Key Laboratory of Salt Lake Geology and Environment of Qinghai Province, Xining 810000, P.R.China)
}

Abstract: The Qaidam Basin represents an important provenance for potassium salt in China and in the world. So far, studies have mostly focused on potassium salt in shallow subsurface salt lakes, whereas little has been reported about potassium salt in deep clastic pores. In the present study, the spatial-temporal evolutions involved in the metallogenesis of potassium salt in the Qaidam Basin are summarized within the context of the Kunteyi Sag as an example. A “double-layered potassium salt” model consisting of intercrystalline brine in the $\mathrm{Q}_{\mathrm{p} 2-\mathrm{h}}$ salt-lake facies chemical salt crystal fissures underlain by the $\mathrm{Q}_{\mathrm{p} 1}$ alluvial-proluvial gravel pore brine is established after investigating the local geology, paleo-environment, and brine reservoir distribution in the study area. The genesis of this "double-layered potassium salt" model and the internal connections between the overlying and underlying brine layers are explored by comparing the ionic contents in these layers through mathematical and geochemical approaches such as cluster analysis, characteristic coefficient, piper trilinear nomograph, and hydrogen and oxygen isotopes. The results indicate that within the Qaidam Basin, the brine in the "double-layered potassium salt" unexceptionally comprises salt rock lixiviation water from a continental sedimentary background. The overlying intercrystalline brine suggests more of salt rock dissolution, although lixiviation may have also played a role; the underlying gravel pore brine points more toward rock salt dissolution. The overlying intercrystalline brine seems to

* 2019-03-19 收稿;2019-07-26 收修改稿. 中央地质勘查基金项目 (2013630003)、青海省地质勘查基金项目和青海省自然科学基金项目(2019-ZJ-911)联合 资助.

** 通信作者;E-mail: 369525736@ qq.com. 
originate from the deep evolution of the underlying gravel pore brine, whereas the underlying gravel pore brine appears to be successive from the deep paleo-salt rock layers and the overlying intercrystalline layer. The oilfield water in the Neogene anticlinal structures surrounding the Kunteyi Sag also shows a close genetic connection with the "double-layered potassium salt" brine.

Keywords: Qaidam Basin; potash deposit; intercrystalline brine; gravel pores brine; hydrochemical characteristics; Kunteyi Depression

由于独特的“高山深盆”环境 ${ }^{[1]}$, 柴达木盆地内马海、昆特依、察汗斯拉图、大浪滩一黑北等次级盆地内 发育丰富的盐类物质,在地表一浅地表位置发育固一液相钾盐矿床, 自 2008 年深层卤水勘查项目实施以 来, 普遍在盆地内揭露到早更新世砂砾石孔隙卤水. 以昆特依凹陷为例, 从上世纪末至今, 针对昆特依凹陷 内浅部钾盐矿床先后开展过地质特征 ${ }^{[2-4]}$ 、古地理 ${ }^{[5]}$ 、古气候 ${ }^{[6-8]}$ 、地球化学 ${ }^{[9]}$ 、水文特征 ${ }^{[10]}$ 和蒸发试验等 ${ }^{[11]}$ 系统而全面的研究. 2014 年首个深部钻孔的实施, 揭露了大厚度的新型砂砾孔隙卤水矿层, 具有单井涌水量 大、品位高、水位埋藏浅、储量大等特点. 前人对大浪滩一黑北凹地地区砂砾孔隙卤水相继开展地震 ${ }^{[12]}$ 、测 井 ${ }^{[13]}$ 等工作手段, 并进行了水化学 ${ }^{[14]}$ 、古环境 ${ }^{[15]}$ 、古气候 ${ }^{[16]}$ 及成因方面 ${ }^{[17]}$ 研究, 初步建立了砂砾孔隙卤水 成矿模式 ${ }^{[18]}$. 但对于昆特依凹陷内深层砂砾石孔隙卤水的研究尚未开展, 且浅部卤水与深部卤水的关系尚 未明确, 故此次研究以昆特依凹陷内上层化学晶间卤水及下层砂砾孔隙卤水为研究对象, 首次提出昆特依 凹陷钾盐“双层模式”,对柴达木盆地内钾盐成盐成矿进行论述,为今后盆地内钾盐成矿规律研究提供依据.

\section{1 地质背景介绍}

昆特依凹陷是柴达木盆地柴北缘块断带的次级断陷盆地,位于大地构造单元一昆仑禇皱系和祁连禇皱 系内, 经历了自吕梁至喜山长期而复杂的构造运动, 表现为十分发育的断块和强烈的禇皱. 凹陷北以阿尔金 山为界, 东临由冷湖 $I \sim V$ 号 5 个背斜组成的冷湖构造带, 西接俄博梁 I III 号背斜, 受阿尔金山走滑运动 的影响, 冷湖构造带和鄂博梁构造带均表现为典型的反 “ $S$ ” 型构造 (图 1); 盆地南部为葫芦山背斜构造带; 昆特依盆地北侧的小红山断裂 $\left(F_{1}\right)$ 和西南侧发育的双气泉断裂 $\left(F_{9}\right)$ 两条大断裂, 共同组成了昆特依盆地的 边缘断裂.

昆特依凹陷内大部分地表出露第四系湖积、化学沉积地层和少量风成沉积地层. 控制凹陷边界的冷湖、 鄂博梁构造带以及葫芦山背斜构造则普遍发育新近纪地层, 且地层出露完整, 从上干柴沟组 $\left(\mathrm{N}_{1} g\right)$ 至狮子沟 组 $\left(\mathrm{N}_{2} s\right)$ 均有发育, 局部背斜核部出露古近纪下干柴沟组地层 $\left(\mathrm{E}_{3} g\right)$. 在凹陷北部、北东部分别有阿尔金山 基岩岩系地层出露. 昆特依凹陷内发育大盐滩、大熊滩、俄博滩、北部新盐带、钾湖 5 个矿田, 尤以大盐滩面 积最广, 属于以液体矿为主的固液并存的盐湖矿床. 从地表向下 $20 \mathrm{~m}$, 局部可达 $335 \mathrm{~m}$, 广泛分布厚度稳定 的多层固体盐类沉积物, 包括石盐、光卤石、芒硝、杂卤石等, 局部矿体呈似层状、透镜体状展布. 液体矿层大 多分布在新近系背斜构造之间的向斜洼地中, 局部在山前冲洪积平原前缘的低洼处也有分布, 具有层数多 的特点, 含矿层主要为盐岩沉积层、粗碎屑层及细碎屑层等 (图 2). 此外, 在昆特依凹陷四周的冷湖、俄博梁 背斜构造带,多发育和油气资源伴生、赋存在裂隙孔隙中的高矿化油田水.

根据液态卤水的赋存介质和空间不同可将凹陷内卤水划分为化学岩类晶间水、松散岩类孔隙水、碎屑 岩类裂隙孔隙水和基岩裂隙水 4 类. 化学盐类晶间水主要分布在地表一浅地表中更新世一全新世化学盐类 沉积层中, 松散岩类孔隙水主要赋存在山前早更新世冲洪积相粗颗粒地层内, 碎屑岩类裂隙孔隙水则分布 在凹陷边缘新近纪背斜构造的裂隙以及岩屑孔隙中,基岩裂隙水主要分布在阿尔金山及深大断裂内.

昆特依矿区施工的 3 个深部钻孔, 均在 $150 \mathrm{~m}$ 以下揭露到早更新世沉积的巨厚的冲洪积相沉积, 与上覆 沉积物整合接触, 岩性多为粉砂、细砂、中粗砂、含砾中粗砂, 富含高矿化度卤水, 矿化度普遍大于 $250 \mathrm{~g} / \mathrm{L}$, $\mathrm{KCl}$ 品位除个别样品外均大于边界品位, 普遍介于 $0.30 \% \sim 0.48 \%$ 之间, 且单井涌水量超过 $6000 \mathrm{~m}^{3} / \mathrm{d}$, 富水 性强, 具有极好的工业利用前景.

受多期复杂的构造运动影响, 在凹陷北部边缘发育北西一东西向深大断裂, 在凹陷内部新近纪背斜构造 带发育系列近南北向断裂 ${ }^{[19]}$, 这些丰富的断裂不仅和新近系背斜构造带一起控制着凹陷内盐岩层的空间分 布, 也为大气降水、油田水和深部水的运移及物质交换的发生提供良好运移通道和存储空间, 并在一定程度 上影响凹陷内卤水的演化. 因第四纪干冷和湿暖交替的古气候特点 ${ }^{[20]}$, 昆特依凹陷内呈现多期的沉积旋 


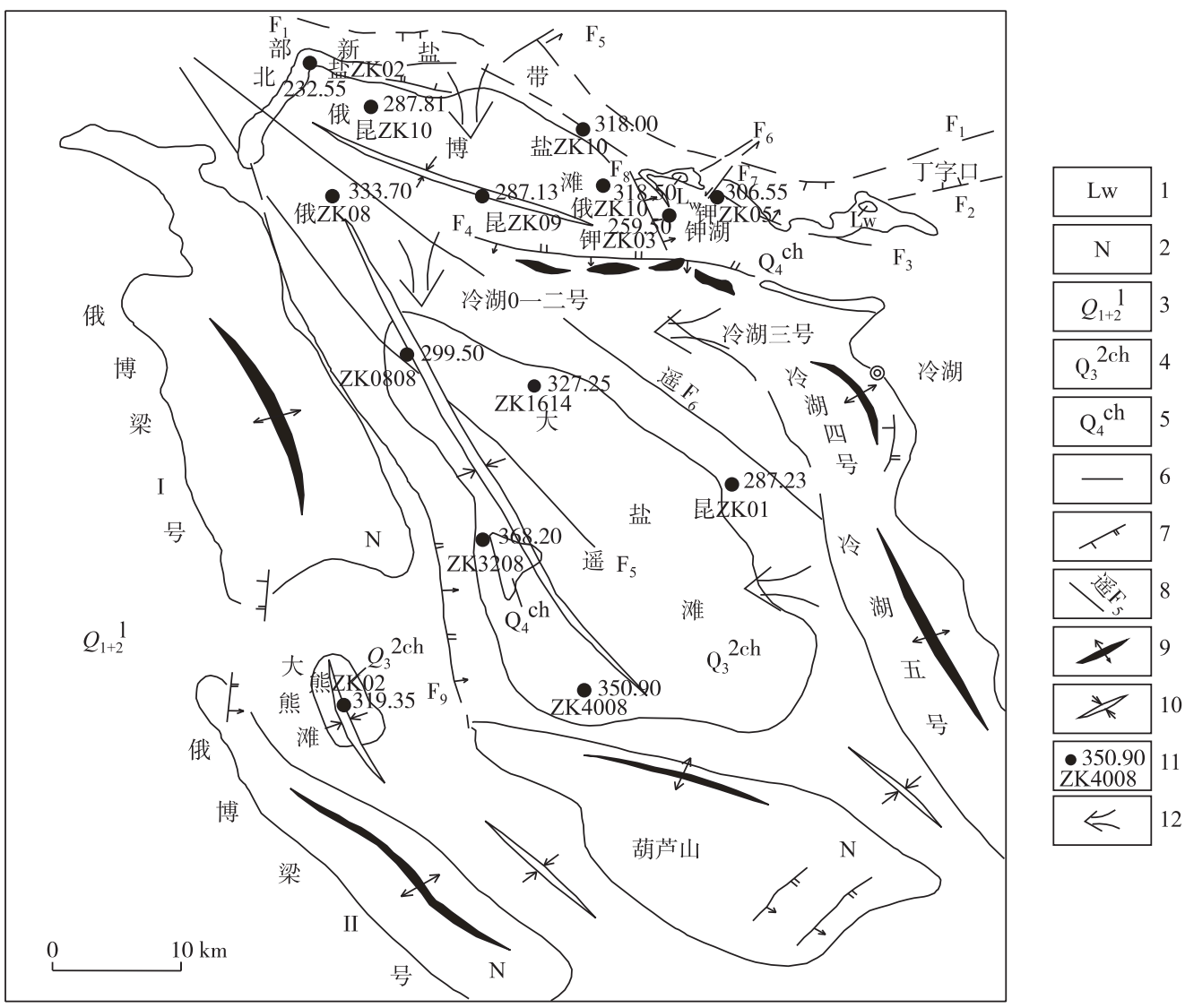

图 1 昆特依凹陷地质略图

( 1 湖水; 2 新近系; 3 中下更新统湖积; 4 上更新统化学沉积; 5 全新统化学沉积; 6 基底断裂; 7 断裂; 8 遥感解译断层;9 背斜; 10 向斜; 11 钻孔编号及矿化度; 12 浓缩方向 )

Fig.1 Geological sketch map of Kunteyi Depression

( 1 lake water; 2 Neogene; 3 lacustrine deposit of middle-lower Pleistocene; 4 chemical deposition of upper Pleistocene; 5 chemical deposition of Holocene; 6 basement fault; 7 fault; 8 fault of remote sensing interpretation; 9 anticline; 10 syncline; 11 drill number and TDS; 12 concentration direction)

回, 每个旋回有一层或多层的石盐和泥岩层 ${ }^{[8]}$, 具体表现为碎屑岩层、含盐碎屑岩层与固、液态矿体的互层, 这也是昆特依凹陷内多矿层的成因. 尽管经历了多次干冷和暖湿的气候波动, 但是由于 “高山深盆” 环境, 加 之日趋干旱的气候条件,强烈蒸发是影响昆特依凹陷盐湖演化的主要因素.

昆特依凹陷内卤水沉积矿层可分为上下两层, 上部为中更新世一全新世化学沉积晶间层,下部为早更新 世砂砾石孔隙层:

1) 上部化学沉积晶间层:上部化学沉积晶间卤水是卢水演化至后期的产物,赋存在中更新统一全新统湖 相一盐湖相之间的盐岩晶隙和裂隙中, 埋藏深度不超过 $95 \mathrm{~m}$, 自上而下按产出时代、赋存条件等可划分为 4 个卤水矿层, 主要呈层状、似层状、条带状展布, 局部呈透镜体状 (图 2), 其储卤介质主要为石盐、含粉砂的石 盐、含芒硝的石盐、含黏土 (淤泥) 的石盐和含石盐的芒硝等, 其间有较稳定的隔水层. 凹陷中心大盐滩、鄂博 滩水化学类型主要为硫酸镁亚型,在边缘北部新盐带、钾湖等地水化学类型多为氯化物型.

2)下部砂砾石孔隙层: 在地表 $136 \mathrm{~m}$ 以下, 高矿化度卤水赋存在早更新世冲洪积相砂砾石孔隙、构造裂 隙中, 含水层厚度最小为 $248.56 \mathrm{~m}$, 最大可达 $805.00 \mathrm{~m}$, 岩性为砂、砾石互层 (夹卵石、漂石), 中细砂、粗砂, 


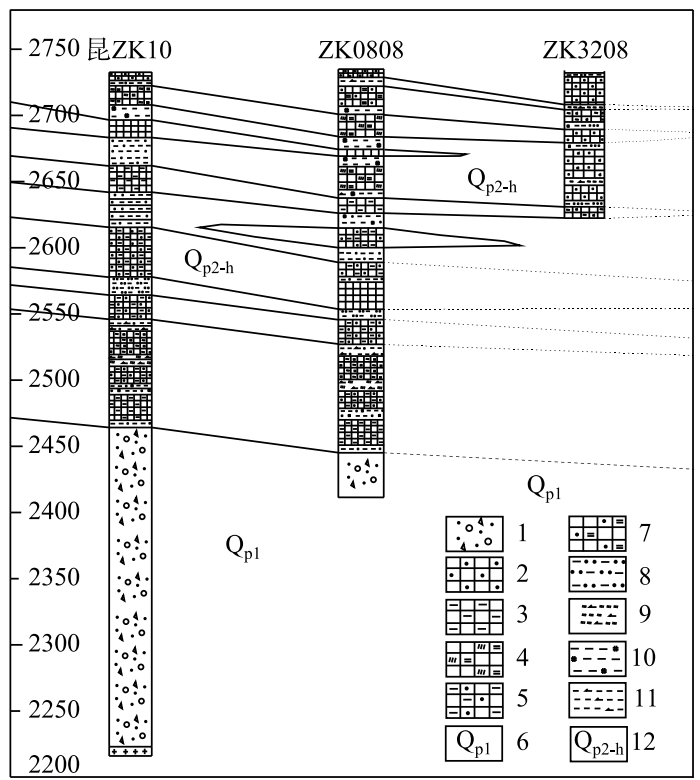

图 2 昆特依凹陷剖面示意图

(1 砂砾石;2 含粉砂石盐;3 含黏土石盐;4 含淤泥芒硝之石盐;5 含泥砂石盐;6 早更新世;

7 含芒硝粉砂的石盐;8 含黏土粉砂;9 含石膏淤泥; 10 含石盐黏土;11 含芒硝黏土;12 中更新世一全新世)

Fig.2 Profile schematic diagram of Kunteyi Depression

( 1 sandy gravel; 2 silt-bearing halite; 3 clay-bearing halite; 4 ooze-bearing mirabilite halite;

5 mud and sand bearing halite; 6 early Pleistocene; 7 mirabilite-bearing silt halite; 8 clay-bearing silt;

9 gypsum-bearing ooze; 10 halite-bearing clay; 11 mirabilite-bearing clay; 12 middle Pleistocene-Holocene)

含黏土的砂砾石等. 彼此之间为渐变接触关系, 上下并没有稳定的隔水层, 仅有少量薄层黏土层分布于其间. 水化学类型均为氯化物型. 下部砂砾石孔隙卤水层赋存的冲洪积相沉积与上覆化学沉积晶间层赋存的湖 相一盐湖相沉积之间呈整合接触, 上下两层卤水虽然储卤介质不同, 但是并不排除通过断层或越流补给等方 式发生物质的交换的可能.

\section{2 样品采集及测试}

钻孔完成取芯工作后下人管材成井, 然后采用拉活塞等方法洗孔, 直至水清砂净, 进行抽水试验. 抽水 试验过程中采样间隔为 $4 \mathrm{~h}$. 用蒸馏水洗净的瓶子取 $1 \mathrm{~L}$ 卤水, 取样后及时用蜡密封瓶口, 编号送样. 常量离 子 $\mathrm{K}^{+} 、 \mathrm{Na}^{+} 、 \mathrm{Ca}^{2+} 、 \mathrm{Mg}^{2+} 、 \mathrm{HCO}_{3}^{-} 、 \mathrm{SO}_{4}^{2-} 、 \mathrm{Cl}^{-}$等用常规重量法( 误差 $0 \% \sim 5 \%$ ) 和滴定法( 误差 $0.2 \% \sim 0.3 \%$ ) 测定， 微量离子 $\mathrm{Li}^{+} 、 \mathrm{I}^{-} 、 \mathrm{Br}^{-}$等含量采用原子吸收光谱法(误差小于 $2 \%$ ) 进行测定, 吸光光度法 (误差小于 $1 \%$ ) 则用 于测定 $\mathrm{B}^{3+}$ 离子含量.

\section{3 结果}

\section{1 主要离子组成}

晶间卤水受补给、径流、埋藏条件的影响,上部晶间卤水明显表现出自东向西、自北向南逐渐浓缩, 矿化 度不断增高的趋势 (图 1、表 1). $\mathrm{K}^{+}$和 $\mathrm{Mg}^{2+}$ 浓度变化范围较大, $\mathrm{K}^{+}$介于 $2.68 \sim 10.68 \mathrm{~g} / \mathrm{L}$ 之间, $\mathrm{Mg}^{2+}$ 浓度最小 值为 $6.30 \mathrm{~g} / \mathrm{L}$, 最大值为 $28.52 \mathrm{~g} / \mathrm{L}, \mathrm{SO}_{4}^{2-}$ 浓度最高为 $68.15 \mathrm{~g} / \mathrm{L}, \mathrm{Cl}^{-}$则分布在 $160.22 \sim 199.58 \mathrm{~g} / \mathrm{L}$ 之间, 矿化 度多数大于 $300 \mathrm{~g} / \mathrm{L}, \mathrm{pH}$ 值分布范围为 7.00 8.23, 卤水普遍偏碱性; $\mathrm{B}_{2} \mathrm{O}_{3}$ 浓度多数大于 $100 \mathrm{mg} / \mathrm{L}$, 最高可达 $450 \mathrm{mg} / \mathrm{L}$, 体现卤水的浓缩. 根据瓦氏分类水化学类型为硫酸镁亚型和氯化物型. 


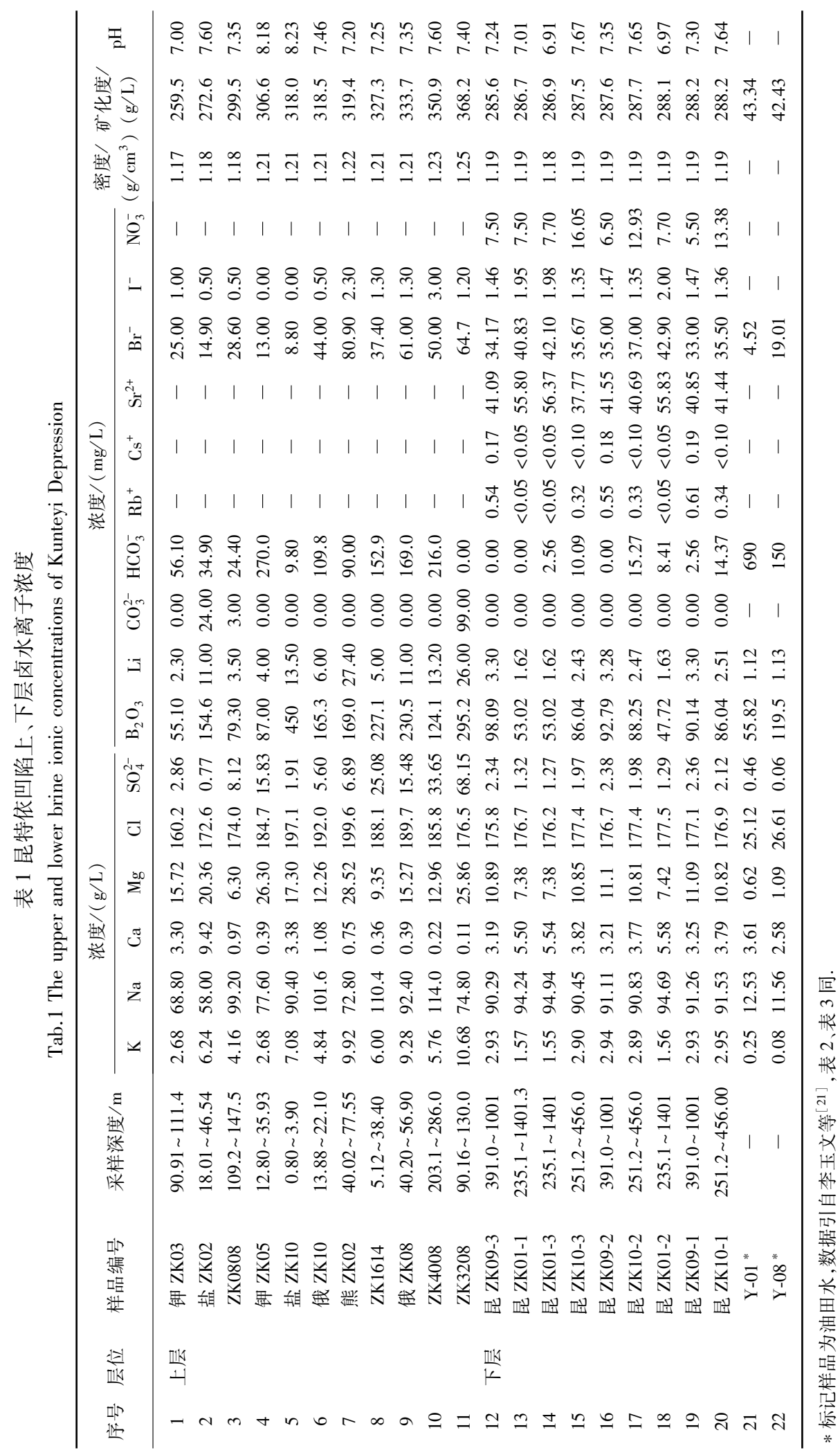


深部砂砾石孔隙卤水各离子含量以及密度、矿化度和 $\mathrm{pH}$ 分布更为集中稳定, 密度均为 $1.19 \mathrm{~g} / \mathrm{cm}^{3}$, 矿 化度分布在 $285 \sim 288 \mathrm{~g} / \mathrm{L}$ 之间, 且 $\mathrm{pH}$ 值约为 7.0 左右, $\mathrm{Na}^{+}$浓度均大于 $90 \mathrm{~g} / \mathrm{L}, \mathrm{Ca}^{2+}$ 浓度均大于 $3.00 \mathrm{~g} / \mathrm{L}, \mathrm{Cl}^{-}$ 浓度为 $175.80 \sim 177.50 \mathrm{~g} / \mathrm{L}$, 但 $\mathrm{B}_{2} \mathrm{O}_{3}$ 值较低, 均小于 $100 \mathrm{mg} / \mathrm{L}$, 水化学类型均为氯化物型. 相较而言, 上层晶 间卤水有更高的 $\mathrm{K}^{+} 、 \mathrm{Mg}^{2+} 、 \mathrm{SO}_{4}^{2-} 、 \mathrm{~B}_{2} \mathrm{O}_{3} 、 \mathrm{Li}^{+}$、矿化度和 $\mathrm{pH}$. 下层砂砾石孔隙卤水有更高的 $\mathrm{Ca}^{2+}$ 浓度和更低的 $\mathrm{pH}$ 值.

钾湖晶间卤水样品中 $\delta^{18} \mathrm{O}$ 分布集中在 $-8.20 \%$ $7.80 \%$ 之间, 大盐滩晶间卤水的 $\delta^{18} \mathrm{O}$ 分布较为集中, 在 $-4.20 \% 0 \sim 4.60 \%$ 之间, $\delta \mathrm{D}$ 分布范围较大, 最小值为 $-53.50 \%$, 最大值为 $-6.10 \%$, 油田水的 $\delta \mathrm{D}$ 分布区间较 宽,为 $-75.60 \% \sim-32.5 \%, \delta^{18} \mathrm{O}$ 分布在 $-6.50 \% \sim-6.06 \%$ 之间.

\section{2 离子特征系数}

从表 2 可见,上层晶间卤水的钠氯系数介于 $0.52 \sim 0.95$ 之间, 过半的样品脱硫系数小于 1.00 , 多分布在 凹陷边缘地区, 凹陷中心样品脱硫系数普遍大于 1.00 . 下层砂砾孔隙卤水的钠氯系数分布于 $0.79 \sim 0.83$ 之 间, 脱硫系数最小值为 0.13 , 最大值为 0.25 , 均小于 0.30 . 相较而言, 上层晶间卤水有更低的钠氯系数和更高 的脱硫系数比值.

$\mathrm{Na} / \mathrm{Br}$ 比值的变化可以用于推断盐类的起源 ${ }^{[23]}$. 在昆特依 $\mathrm{Cl} / \mathrm{Br}-\mathrm{Na} / \mathrm{Br}$ 图 ${ }^{[24]}$ 中, 海水点 ${ }^{[25]}$ 落在靠近原 点位置, 上层卤水分布范围较下层卤水分布范围大, 且研究区内卤水中所有样品及冷湖 III 、 IV 号构造中油田 水表现出一定的线性关系说明区域地下卤水矿层具有相似来源特征(图 3).

\section{3 聚类分析特征}

为总结昆特依凹陷上、下两层卤水各离子的分布规律, 按照变量对其含量进行聚类分析 (图 4), $\mathrm{Na}^{+}$、 $\mathrm{Cl}^{-}$、密度、矿化度和 $\mathrm{pH}$ 聚为一类, $\mathrm{Br}^{-} 、 \mathrm{I}^{-}$和 $\mathrm{Ca}^{2+}$ 聚为一类, $\mathrm{K}^{+} 、 \mathrm{Li}^{+} 、 \mathrm{~B}_{2} \mathrm{O}_{3}$ 和 $\mathrm{Mg}^{2+}$ 聚为一类, $\mathrm{SO}_{4}^{2-}$ 和 $\mathrm{CO}_{3}^{2-}$ 聚为一 类后与 $\mathrm{HCO}_{3}^{-}$聚为一亚类.

\subsection{Piper 三线图特征}

根据 piper 三线图可以进行卤水演化分析 ${ }^{[26-27]}$, 昆特依凹陷上下层卤水及油田水的阳离子主要是 $\mathrm{Na}^{+}$和 $\mathrm{K}^{+}$, 还有少量的 $\mathrm{Ca}^{2+}$, 主要阴离子为 $\mathrm{Cl}^{-}$, 其次为 $\mathrm{SO}_{4}^{2-}$, 均呈带状分布在左、右下方的三角形右边界部位 (图 $5)$, 其分布大致相同但略有差异.

\section{5 氢一氧同位素特征}

研究区中部大盐滩的硫酸镁亚型卤水、盆地边缘钾湖的氯化钠型卤水以及深部氯化钙型的油田水 $\delta \mathrm{D}-$ $\delta^{18} \mathrm{O}$ (表 3) 关系如图 6 所示. 可见其全部分布在大气降水线的下方, 表现出蒸发浓缩的特征,且这 3 种类型 的卤水呈现出 3 种不同端元水的特征.

\section{4 双层钾盐模式讨论}

根据聚类分析图 (图 4) 可见石盐溶解影响着卤水的密度、矿化度以及 $\mathrm{pH}$, 地表强烈的风化作用带来丰 富的 $\mathrm{Ca}^{2+} 、 \mathrm{Br}^{-}$以及 $\mathrm{I}^{-}$. 瓦里亚什科指出, 硫酸盐水体会发生正向变质作用:

$$
\mathrm{MgSO}_{4}+\mathrm{Ca}\left(\mathrm{HCO}_{3}\right)_{2} \rightleftharpoons \mathrm{Mg}\left(\mathrm{HCO}_{3}\right)_{2}+\mathrm{CaSO}_{4}
$$

其中 $\mathrm{Mg}\left(\mathrm{HCO}_{3}\right)_{2}$ 会继续分解为 $\mathrm{xMg}(\mathrm{OH})_{2} \cdot \mathrm{yMgCO}_{3} \cdot \mathrm{zH}_{2} \mathrm{O}^{[28]}$, 故而在昆特依凹陷卤水中, $\mathrm{SO}_{4}^{2-} 、 \mathrm{CO}_{3}^{-}$和 $\mathrm{HCO}_{3}^{-}$ 关系密切. 前人通过对昆特依凹陷内冷湖 III 、 IV 号构造中油田水的研究认为, 碳酸盐、硅酸盐的溶解为 $\mathrm{CaCl}_{2}$ 型油田水提供了 $\mathrm{K} 、 \mathrm{Mg} 、 \mathrm{~B} 、 \mathrm{Li}$ 等元素 ${ }^{[29-30]}$. 和凹陷内上、下层卤水有相似物质来源的深部 $\mathrm{CaCl}_{2}$ 型油田水沿 着张性导水深大断裂向上运移, 补给至上部 (图 7). 简言之, 昆特依凹陷内上、下层卤水在成因上与新近系 背斜构造中的油田水有紧密的联系.

早一中更新世, 大盐滩为昆特依凹陷的沉积中心, 在凹陷北部边缘北部新盐带, 油田水和上部晶间卤水 层发生化学反应:

$$
\mathrm{CaCl}_{2}+\mathrm{MgSO}_{4} \rightleftharpoons \mathrm{CaSO}_{4} \downarrow+\mathrm{MgCl}_{2}
$$

同时沉积石膏, 促进卢水由硫酸盐型向氯化物型演化, 而在凹陷中心大盐滩存在 $\mathrm{NaCl}^{-} \mathrm{Na}_{2} \mathrm{SO}_{4}-\mathrm{H}_{2} \mathrm{O}$ 体 系平衡, $2 \mathrm{NaCl}+\mathrm{MgSO}_{4} \rightleftharpoons \mathrm{MgCl}_{2}+\mathrm{Na}_{2} \mathrm{SO}_{4}$, 沉积芒硝、光卤石、杂卤石等盐类矿物. 晚更新世一全新世, 在暖湿气 候影响下, 沉积中心向北迁移, 同时大气降水溶滤周缘盐岩补给至凹陷, 在凹陷边缘形成氯化物型卤水. 


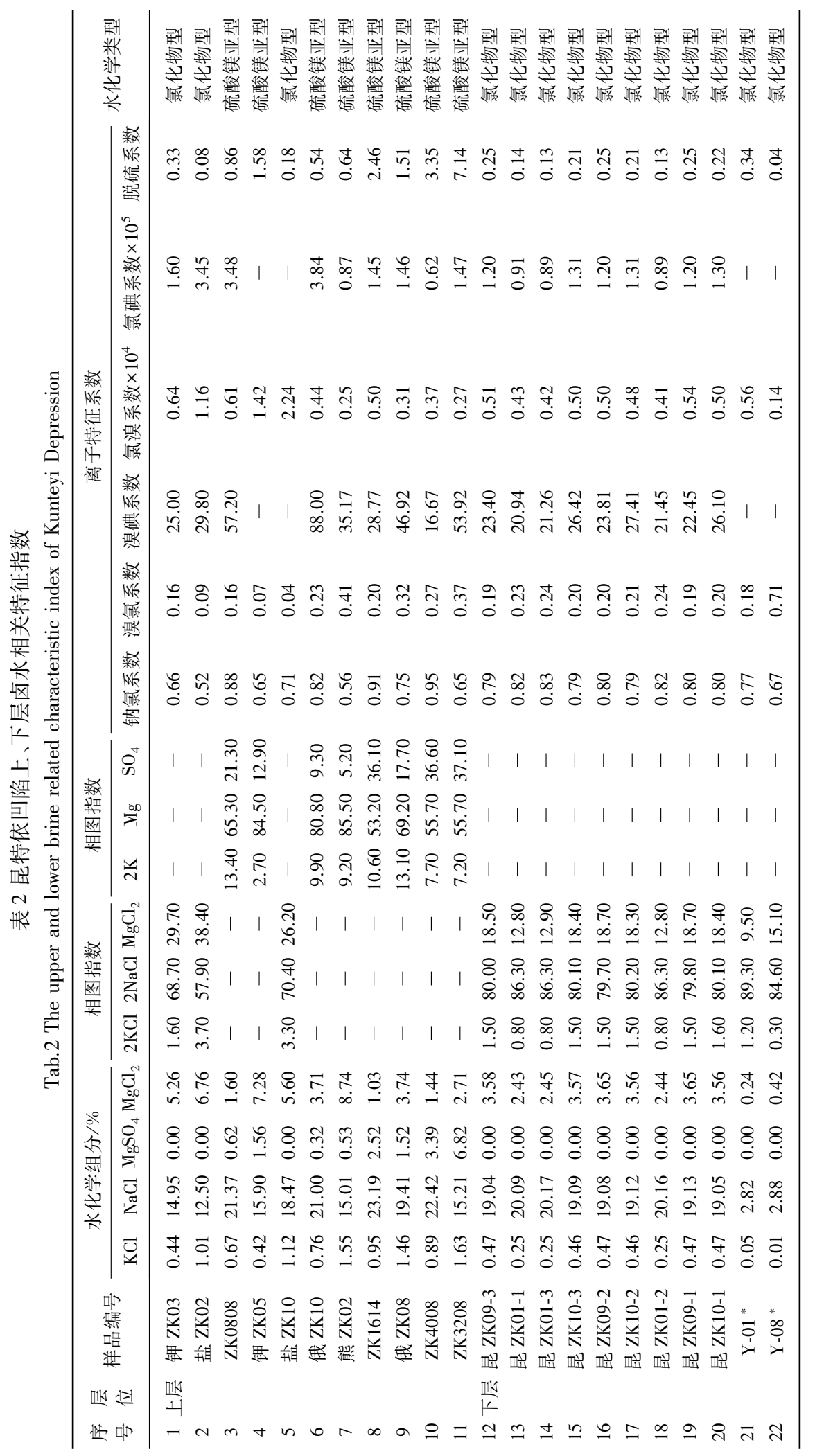


表 3 昆特依凹陷卤水氢氧同位素组成*

Tab.3 Hydrogen and oxygen isotopic compositions of brine from Kunteyi Depression

\begin{tabular}{|c|c|c|c|c|c|c|c|}
\hline 序号 & $\begin{array}{c}\delta \mathrm{D}_{(\mathrm{V} \text {-SMOW })} \\
\% 0\end{array}$ & $\begin{array}{c}\delta^{18} \mathrm{O}_{(\mathrm{V} \text {-SMOW })} \\
\% 0\end{array}$ & 采样地点及类型 & 序号 & $\begin{array}{c}\delta \mathrm{D}_{(\mathrm{V} \text {-SMOW })} \\
\% 0\end{array}$ & $\begin{array}{c}\delta^{18} \mathrm{O}_{(\mathrm{V}-\mathrm{smow})} \\
\% \text { o }\end{array}$ & 采样地点及类型 \\
\hline $1^{*}$ & -81.00 & -8.20 & 钾湖晶间卤水 & 18 & -48.00 & -0.10 & 大盐滩晶间卤水 \\
\hline $2 *$ & -66.00 & -7.80 & 钾湖晶间卤水 & 19 & -46.00 & -3.40 & 大盐滩晶间卤水 \\
\hline $3^{*}$ & -64.00 & -7.80 & 钾湖晶间卤水 & 20 * & -56.40 & -6.50 & 冷湖 III - IV 构造油田水 \\
\hline $4^{*}$ & -71.00 & -7.80 & 钾湖晶间卤水 & $21 *$ & -48.00 & 0.10 & 冷湖 III - IV 构造油田水 \\
\hline $5 *$ & -36.00 & -0.90 & 大盐滩晶间卤水 & $22 *$ & -75.60 & -3.70 & 冷湖 III - IV 构造油田水 \\
\hline $6^{*}$ & -32.00 & -0.20 & 大盐滩晶间卤水 & $23^{*}$ & -44.00 & 3.50 & 冷湖 III - IV 构造油田水 \\
\hline $7 *$ & -6.10 & 4.60 & 大盐滩晶间卤水 & $24 *$ & -39.50 & 3.90 & 冷湖 IIIIIV构造油田水 \\
\hline $8^{*}$ & -26.20 & 0.60 & 大盐滩晶间卤水 & $25^{*}$ & -37.60 & 3.00 & 冷湖 III - IV 构造油田水 \\
\hline $9^{*}$ & -15.00 & 2.10 & 大盐滩晶间卤水 & $26^{*}$ & -35.20 & 3.40 & 冷湖 III -IV 构造油田水 \\
\hline $10^{*}$ & -24.00 & 0.90 & 大盐滩晶间卤水 & $27^{*}$ & -39.70 & 3.00 & 冷湖 III - IV 构造油田水 \\
\hline $11^{*}$ & -37.30 & -20.00 & 大盐滩晶间卤水 & $28 *$ & -32.50 & 6.10 & 冷湖 IIII-IV 构造油田水 \\
\hline $12 *$ & -47.00 & -4.20 & 大盐滩晶间卤水 & $29^{*}$ & -43.30 & 2.30 & 冷湖 IIII-IV构造油田水 \\
\hline $13^{*}$ & -53.50 & -2.10 & 大盐滩晶间卤水 & 30 & -35.20 & 3.36 & 红柳泉油田水 \\
\hline 14 & -52.00 & -2.10 & 大盐滩晶间卤水 & 31 & -39.70 & 2.99 & 冷湖 V 号油田水 \\
\hline 15 & -44.00 & 1.10 & 大盐滩晶间卤水 & 32 & -32.50 & 6.06 & 冷湖 V 号油田水 \\
\hline 16 & -47.00 & -4.20 & 大盐滩晶间卤水 & 33 & -43.30 & 2.30 & 冷潮 2 区油田水 \\
\hline 17 & -53.00 & -2.10 & 大盐滩晶间卤水 & 34 & -44.00 & 3.50 & 双气泉油田水 \\
\hline
\end{tabular}

* 编号 $14 \sim 17$ 数据来源于王弭力等 ${ }^{[22]}$.

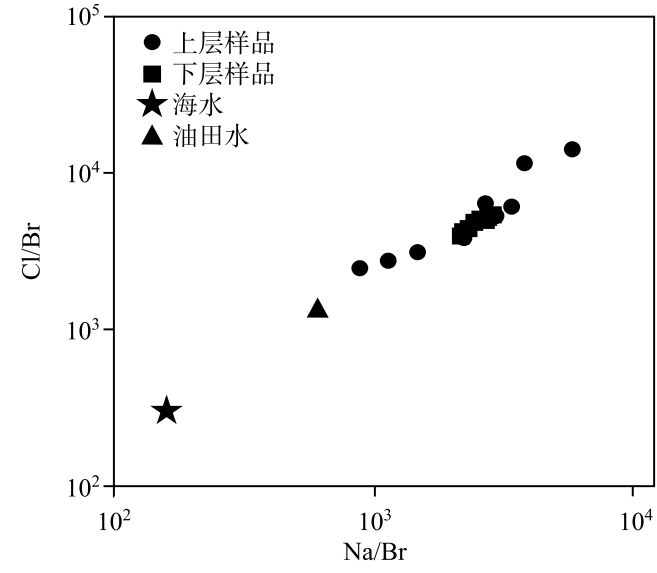

图 3 昆特依凹陷卤水 $\mathrm{Cl} / \mathrm{Br}-\mathrm{Na} / \mathrm{Br}$ 图

Fig. $3 \mathrm{Cl} / \mathrm{Br}-\mathrm{Na} / \mathrm{Br}$ of brine from Kunteyi Depression

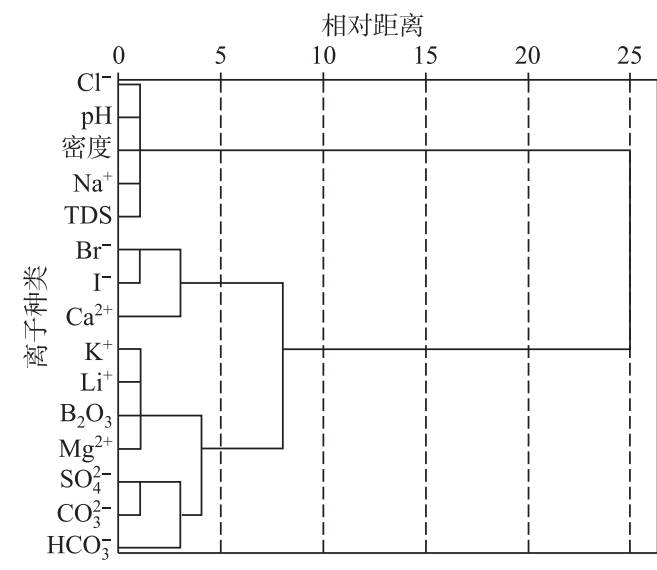

图 4 昆特依凹陷上、下层离子聚类分析

Fig.4 The upper and lower brine ionic cluster analysis of Kunteyi Depression

样品在 Piper 图解上方的菱形中落在右上边界部位, 代表了 $\mathrm{Na}$ 和 $\mathrm{Cl}$ 即石盐的溶解过程, 同时伴随着矿 化度的增高, 昆特依凹陷上下层卤水及油田水大致有向上硫酸盐型和向下氯化物型两个演化方向, 因油田 水和下层砂砾孔隙卤水落在中间部位,无论向上还是向下, 均演化成为上层晶间卤水, 总体体现为: 上层晶 间卤水表现出下层砂砾石孔隙卤水进一步的演化特征, 下部砂砾孔隙卤水与上层晶间层盐岩的溶滤密切 相关.

对卤水中的离子含量进行特征系数分析可了解其成因及演化 ${ }^{[31-32]}$. 当卤水不断蒸发浓缩, 氯化钠开始 


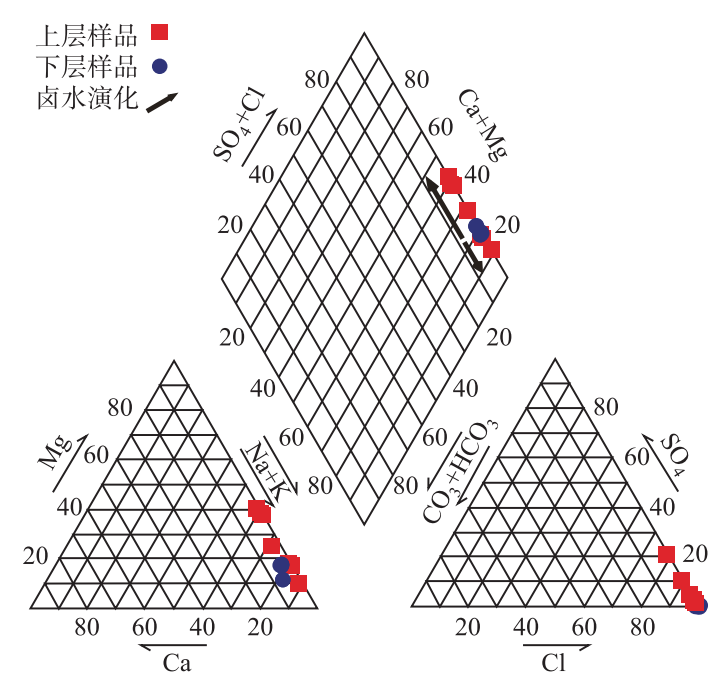

图 5 昆特依凹陷Piper 三线图

Fig.5 Piper trilinear diagram of Kunteyi Depression

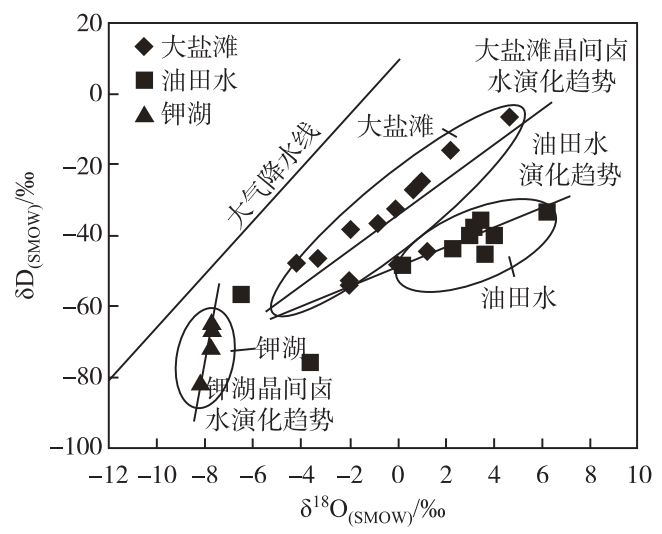

图 6 昆特依凹陷氢氧同位素分布特征

Fig.6 Distribution of hydrogen and oxygen isotopic compositons of brine from Kunteyi Depression

沉淀时, 矿化度在 $250 \sim 275 \mathrm{~g} / \mathrm{L}$, 此时 $\gamma \mathrm{Na} / \gamma \mathrm{Cl}$ 为 0.82 , 蒸发浓缩继续, 随着碳酸盐、硫酸盐的析出和氯元素 进一步富集, 钠氯系数值不断降低, 故而常把 $\gamma \mathrm{Na} / \gamma \mathrm{Cl}$ 小于 0.85 的卤水作为具有古海水特征的沉积卤水 ${ }^{[33]}$. 昆特依凹陷内下层卤水的钠氯系数多分布在 0.82 左右, 而上层卤水的钠氯系数则介于 $0.56 \sim 0.95$ 之间, Fontes 等 ${ }^{[34]}$ 则认为, 蒸发岩的溶解产生更多的 $\mathrm{Cl}^{-}$和更少的 $\mathrm{Br}^{-[35]}$, 综合考虑昆特依凹陷上层卢水由于蒸发 岩的溶解作用, 导致更多的 $\mathrm{Cl}^{-}$进人卤水, 从而引起钠氯系数的降低, 下层卤水的钠氯系数虽表现为沉积卤 水特征, 但其矿化度为 $287 \mathrm{~g} / \mathrm{L}$, 钠氯系数在 0.82 左右, 在 $\mathrm{Cl} / \mathrm{Br}-\mathrm{Na} / \mathrm{Br}$ 图中均落在海水点的上方及右方, 推 测下层卤水来源为石盐的溶解. 上层晶间卤水源于盐岩的溶解, 且蒸发岩溶解水对钾 ZK05、熊 ZK02、盐 ZK02、ZK3208 和钾 ZK03 有更大的影响. 上层晶间卤水的脱硫系数整体上大于下层砂砾石孔隙卤水, 表明下 层的砂砾石孔隙卤水还原性和封闭性优于上层晶间卤水,但 ZK0808、俄 ZK10、熊 ZK02、钾 ZK03、盐 ZK02 和 盐 ZK10 的脱硫系数小于 1 , 尤其是盐 ZK02 和盐 ZK10, 脱硫系数值接近于 0 , 很有可能是因为周围盐类晶体 致密的结构, 形成封闭性好的封存水. ZK3208 则表现出沉积变质卤水 ${ }^{[36]}$ 的特征. 此外, 溴氯系数小于 1 , 溴 碘系数小于 $1300^{[33]}$, 氯碘系数大于 $10^{5}$, 氯溴系数大于 $2500^{[37]}$, 都表明昆特依凹陷中的卤水属于陆相沉积 


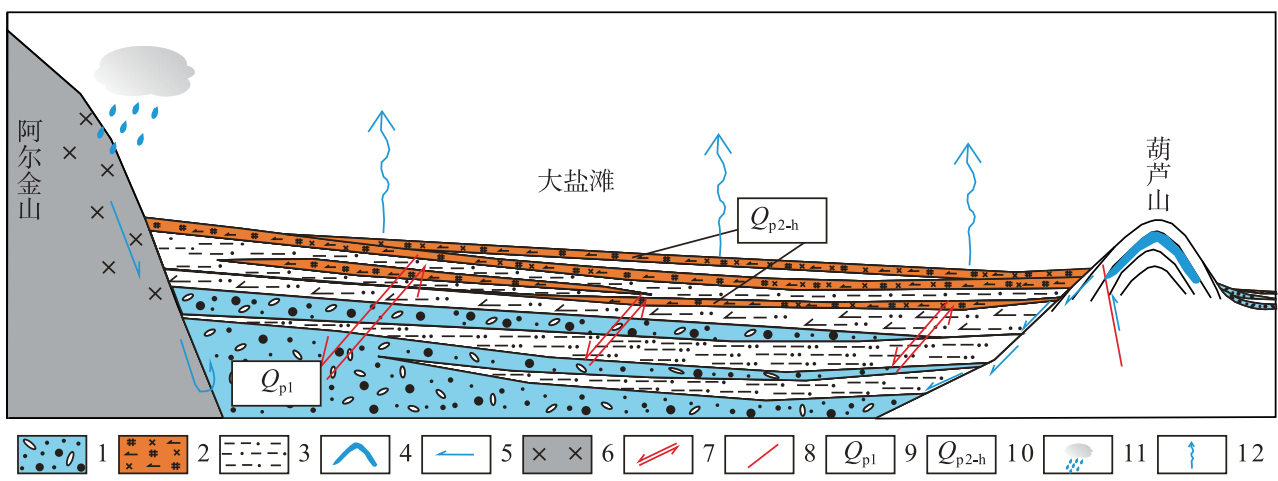

图 7 昆特依凹陷成矿示意图

(1 砂砾孔隙卤水;2 化学盐类晶间卤水;3 湖相沉积;4 油田水;5 水运移方向;6 基岩裂隙;7 物质交换; 8 断裂;9 早更新世; 10 中更新世一全新世; 11 大气降水;12 蒸发作用)

Fig.7 Metallogenic conventional diagram of Kunteyi Depression

( 1 gravel pore brine; 2 chemical salt intercrystalline brine; 3 lacustrine sediment; 4 oilfield brine; 5 migration direction of water; 6 bedrock fissure; 7 material exchange; 8 fault; 9 early Pleistocene; 10 middle Pleistocene- Holocene; 11 meteoric water; 12 evaporation)

环境中形成的溶盐卤水.

在 $\mathrm{Cl} / \mathrm{Br}-\mathrm{Na} / \mathrm{Br}$ 图中, 昆特依凹陷内上、下层卤水与油田水均均落在海水点的右方、上方, 在海水点的 下方和左侧未有分布, 这说明昆特依凹陷中卤水均源自于盐岩的溶解, 并无蒸发残余卤水的参与. 与离子特 征系数的结果相一致, 并且在图 3 中下层卤水样品表现出更为稳定的线性关系, 推测该层卤水源自于石盐 的溶解; 上层卤水的 $\mathrm{Cl} / \mathrm{Br}$ 值有更大的分布范围, 虽大体上呈线性关系, 但熊 ZK02 和盐 ZK02 的 $\mathrm{Cl} / \mathrm{Br}$ 值有 更大的增幅,说明地表蒸发岩的溶解对熊 ZK02 和盐 ZK02 有较大的影响.

在氢氧同位素分布图 (图 6) 中, 钾湖晶间卤水接近大气降水线,但发生了明显的 $\delta \mathrm{D}$ 负漂移,究其原因, 推测钾湖晶间卤水流体来源为大气降水淋滤周边盐岩富集成矿, 因其位于凹陷边缘, 有深部油田水沿着断 裂上升混人, 由于油田水较好的封闭环境, 蒸发量较少, 浓缩了一定量的 ${ }^{1} \mathrm{H}$, 呈现出 $\delta \mathrm{D}$ 较大的负值, 从而导 致钾湖晶间卤水的 $\delta \mathrm{D}$ 负漂移. 李玉文等 ${ }^{[21]}$ 认为 $133 \mathrm{~m}$ 以浅的晶间卤水的形成与油田水的混人有关, 图 6 显 示大气降水线、油田水与大盐滩的晶间卤水呈现 3 种不同的端元水特征, 大盐滩晶间卤水表现出大气降水 和油田水两种不同端元水的混合特征, 经过蒸发浓缩后形成如今的大盐滩晶间卤水. 简言之, 昆特依凹陷内 的卤水起源为早更新世时期大气降水溶滤周缘盐岩中的有用组分并富集在大盐滩一带 (图 7), 其中不乏油 田水的混人,经过蒸发浓缩在早更新世晚期富集成矿, 随着高山深盆环境的形成, 大气降水溶滤围岩及浅部 岩盐层,经裂隙等通道运移至下部以及盆地边缘形成粗颗粒相砂砾石型孔隙卤水.

\section{5 结论}

1) 昆特依凹陷内钾盐矿床具有 “双层” 模式: 上层为中晚更新世一全新世晶间卤水, 下层为早更新世砂 砾石孔隙卤水. 上层晶间卤水的赋存在盐湖相石盐、含粉砂的石盐等盐类、含碎屑岩类晶体裂隙中; 下层砂 砾石孔隙卤水赋存在冲洪积相孔隙度良好的砂砾石、含砾中粗砂.

2) 昆特依凹陷中的上、下层卤水属于陆相沉积环境中形成的溶盐卤水, 均来自于盐岩溶解, 下层卤水来 源于石盐溶解, 表现出对深部古岩层以及地表晶间层的继承性. 上层卤水还有地表风化岩石的溶滤水的加 人,局部表现有沉积变质卤水的特征.

3) 上层晶间卤水表现出下层砂砾石孔隙卤水进一步的演化特征, 下部砂砾孔隙卤水与上层晶间层盐岩 的溶滤密切相关.

4) 昆特依凹陷内具有深部 $\mathrm{CaCl}_{2}$ 特征的油田水沿张性深大断裂上升, 影响上、下层卤水化学组成, 并在 
某种程度上促进上层晶间卤水的演化,上、下层卤水在成因上与深部油田水有紧密联系.

致谢: 感谢项目组野外人员汪青川、蔡进福等人员的全力支持; 文中所有测试工作由青海省柴达木综合地质 矿产勘查院岩矿测试中心完成, 感谢各位测试人员的及时工作.

\section{6 参考文献}

[ 1 ] Yuan JQ, Huo CY, Cai KQ. The high mountain-deep basin saline environment-a new genetic model of salt deposits. Geological Review, 1983, 29(2): 159-165. DOI: 10.16509/j.georeview.1983.02.008. [袁见齐, 霍承禹, 蔡克勤. 高山深 盆的成盐环境——种新的成盐模式的剖析. 地质论评, 1983, 29(2) : 159-165.]

[ 2 ] Zhang Y, Gao DL, Ren QH et al. Permeability of unconfined aquifer under the Dayantan mine area near the Kunty Salt Lake in the Qaidam Basin. Arid Zone Reserach, 2017, 34(1) : 36-42. DOI: 10.13866/j.azr.2017.01.05. [张岩, 高东林, 任倩慧等. 柴达木盆地昆特依盐湖大盐滩矿区潜水含水层的渗透性. 干旱区研究, 2017, 34(1): 36-42.]

[ 3 ] Yang XM, Liu WY, Han FQ et al. Application of Nuclear Magnetic Resonance ( NMR) technology to study the space distribution features of underground brine from playa lakes: a case study of Kunteyi Playa Lake. J Lake Sci, 2018, 30(1): 220-233. DOI: 10.18307/2018.0122. [杨修猛, 刘文玉, 韩风清等. 应用核磁共振技术分析干盐湖地区地下卤水空 间分布特征——以昆特依干盐湖为例. 湖泊科学, 2018, 30 (1) : 220-233. DOI: 10.18307/2018.0122.]

[ 4 ] Yuan XL, Sheng JC, Zhang XY et al. Influence of shallow reservoir upon the components of brines in the Kunteyi Playa. Hydrogeology \& Engineering Geology, 2018, 45(2): 13-20. [袁小龙, 盛金昌, 张西营等. 昆特依盐湖浅部储卤层对 卤水组成的影响. 水文地质工程地质, 2018, 45(2): 13-20.]

[ 5 ] Li FJ, Meng LN, Fang CG et al. Palaeogeographic evolution of the Paleogene and Neogene in north margin of Qaidam Basin. Journal of Palaeogeography, 2012, 14(5) : 596-606. DOI: 10.7605/gdlxb.2012.05.005. [李凤杰, 孟立娜, 方朝刚 等. 柴达木盆地北缘古近纪一新近纪古地理演化. 古地理学报, 2012, 14(5): 596-606.]

[ 6 ] Liu WG, Xiao YK, Han FQ et al. Characteristics of chlorine isotopes in salt lakes of Kunteyi and their significance of paleoclimate. Oceanologia et Limnologia Sinica, 1998, (4) : 431-435. DOI: 10.1088/0256-307X/15/12/024. [ 刘卫国, 肖应凯, 韩风清等. 昆特依盐湖氯同位素特征及古气候意义. 海洋与湖沼, 1998, (4) : 431-435.]

[ 7 ] Zeng FM, Xiang SY. Magnetic susceptibility of Kunteyi Salt Lake during the Late Quaternary and Its Paleoclimatic Significance. Journal of Salt Lake Research, 2017, 25(1): 1-7. [曾方明, 向树元. 柴达木盆地昆特依盐湖磁化率特征及古 气候意义. 盐湖研究, $2017,25(1): 1-7$.

[ 8 ] Han FQ, Huang Q, Wang KJ et al. Study of geochemical evolution and palaeoclimatic fluctuation of Kunteyi salt lake in the Qaidam Basin, Qinghai. Oceanologia et Limnologia Sinica, 1995, (5): 502-508. [ 韩风清, 黄麒, 王克俊等. 柴达 木盆地昆特依盐湖的地球化学演化与古气候变化. 海洋与湖沼, 1995, (5): 502-508.]

[ 9 ] Ren QH, Gao DL, Zhang Y et al. The geochemistry characteristics analysis of brine in Kunty Salt Lake, Qaidam Basin. Journal of Salt Lake Research, 2018, 26(2) : 34-42. DOI: 10.12119/j.yhyj.201802005. [任倩慧, 高东林, 张岩等. 柴 达木盆地昆特依盐湖大盐滩矿区卤水地球化学特征分析. 盐湖研究, 2018, 26(2): 34-42.]

[10] Li YW. The geochemical characteristics and origin of the potassium-rich brine from Kunteyi salt lake in the Qaidam Basin [Dissertation]. Xining: University of Chinese Academy of Sciences( Qinghai Institute of Salt Lakes, CAS), 2018. [李玉 文. 柴达木盆地昆特依盐湖富钾卤水地球化学特征及成因 [学位论文]. 西宁: 中国科学院大学 (中国科学院青海 盐湖研究所), 2018.]

[11] Zhu JR, Zhang ZH, Dong SF et al. The law of precipitation of mineral salts about the brine of Kunteyi Salt Lake by natural eaporation and its mathematical model. Journal of Salt and Chemical Industry, 2011, 40(4): 39-42. [ 朱建荣, 张志宏, 董生发等. 昆特依盐湖卤水自然蒸发析盐规律及模型建立. 盐业与化工, 2011, 40(4): 39-42.]

[12] Li Q, Li YJ, Yang QQ et al. Depositional system and seismic response of subsurface brines reservoirs in western Qaidam Basin, China. Acta Geologica Sinica, 2014, 88(S1) : 425-426.

[13] Li HP, Zheng MP, Liu Y et al. Logging response characteristics for pore brine potassium reservoir in the east of Qaidam Basin. Acta Geologica Sinica, 2014, 88(S1) : 220-221.

[14] Li HP, Zheng MP, Hou XH et al. Hydrochemistry characteristics and origin of new brine sandy gravel in early Pleistocene of Heibei concave in Qaidam Basin. Earth Science-Journal of China University of Geosciences, 2014, 39(10) : 1433-1442. DOI: 10.3799/dqkx.2014.125. [李洪普, 郑绵平, 侯献华等. 柴达木黑北凹地早更新世新型砂砾层卤水水化学特征 
与成因. 地球科学(中国地质大学学报), 2014, 39(10): 1433-1442.]

[15] Qin YP, Hou XH, Zheng MP et al. Magnetostratigraphy of Liang-ZK02 borehole in Dalangtan, Qaidam Basin and its paleoenvironmental significance. Geological Review, 2012, 58(3) : 553-564. DOI: 10.16509/j.georeview.2012.03.017. [秦 永鹏, 侯献华, 郑绵平等. 柴达木盆地大浪滩梁-ZK02 孔的磁性地层及其古环境研究. 地质论评, 2012, 58(3): 553-564.]

[16] Hou XH, Zheng MP, Zhang CJ et al. Sedimentary characteristics and paleoenvironmental of Dalangtan Salt Lake in western Qaidam Basin, since 140 kaBP. Acta Geoscientica Sinica, 2010, 84(11): 1623-1630. [侯献华, 郑绵平, 张成君等. 柴 达木盆地西部大浪滩 $140 \mathrm{ka}$ 以来沉积特征与古环境. 地质学报, 2010, 84(11) : 1623-1630.]

[17] Zheng MP, Zhang XF, Hou XH et al. Geological environments of the late Cenozoic lakes and salt-forming and oil-gas poolforming actions in the Tibetan Plateau. Acta Geoscientica Sinica, 2013, 34(2) : 129-138. DOI: 10.3975/cagsb.2013.02. 01. [郑绵平, 张雪飞, 侯献华等. 青藏高原晚新生代湖泊地质环境与成盐成藏作用. 地球学报, 2013, 34(2): 129-138. ]

[18] Zheng MP, Hou XH, Yu CQ et al. The leading role of salt formation theory in the breakthrough and important progress in potash deposit prospecting. Acta Geoscientica Sinica, 2015, 36(2) : 129-139. DOI: 10.3975/cagsb.2015.02.01. [郑绵平, 侯献华, 于常青等. 成盐理论引领我国找钾取得重要进展. 地球学报, 2015, 36(2)：129-139.]

[19] Li CG. Study on the application of integrated data image processing technology of energy spectrum logging, remote sensing and geoscience exploration in the exploration of potassium salt in Kunteyi salt lake, Qinghai//China Geophysical Society, American Computer Society for Geosciences. Abstracts of papers from the International Symposium on the Application of Computers in Geosciences, 1991. [李昌国. 能谱测井、遥感、物探等综合数据图象处理技术在青海昆特依盐湖钾盐 勘查中的应用研究//中国地球物理学会、美国面向地学的计算机学会. 计算机在地学中的应用国际讨论会论文摘 要集, 1991.]

[20] Zheng MP, Yuan HR, Zhang YS et al. Regional distribution and prospects of potash in China. Acta Geologica Sinica, 2010, 84(11)：1523-1553. [郑绵平, 袁鹤然, 张永生等. 中国钾盐区域分布与找钾远景. 地质学报, 2010,84 (11) : 1523-1553.]

[21] Li YW, Li JS, Fan QS et al. Origin of deep intercrystalline brine from Dayantan mine area in Qaidam Basin. Journal of Salt Lake Research, 2019, 27 (1): 82-88. DOI: 10.12119/j.yhyj.201901009. [李玉文, 李建森, 㚞启顺等. 柴达木盆. 地大盐滩矿区深层晶间卤水的成因. 盐湖研究, 2019, 27(1):82-88.]

[22] Wang ML, Yang ZC, Liu CL et al eds. Potash deposits and their exploration prospects of saline lakes of the northern Qaidam Basin. Beijing: Geological Press, 1997: 65. [王弭力, 杨智琛, 刘成林等. 柴达木盆地北部盐湖钾矿床及其开发 前景. 北京: 地质出版社, 1997: 65.]

[23] Walter L. Br-Cl-Na systematics in Illinois basin fluids: constraints on fluid origin and evolution. Geology, 1990, 18: 315 318. DOI: 10.1130/0091-7613(1990)0182.3.CO;2.

[24] Jensen GKS, Rostron BJ, Duke MJM et al. Bromine and stable isotopic profiles of formation waters from potash mineshafts, Saskatchewan, Canada. Journal of Geochemical Exploration, 2005, 89(1). DOI: 10.1016/j.gexplo.2005.11.071.

[25] Chen YH. sequence of salt separation and regularity of some trace elements distribution during isothermal evaporation $\left(25^{\circ} \mathrm{C}\right)$ of the Huanghai sea water. Acta Geologica Sinica, 1983, (4): 379-395. [陈郁华. 黄海水 $25^{\circ} \mathrm{C}$ 恒温蒸发的析 盐序列及某些微量元素的分布规律. 地质学报, 1983, (4) : 379-395.]

[26] Wang RJ. Three-line diagram and its hydrogeological interpretation. Engineering Survey, 1983, (6): 6-11. [王瑞久. 三 线图解及其水文地质解释. 工程勘察, 1983, (6) : 6-11.]

[27] Mahmoud AA, Rushdi JT. Hydrochemical characteristics of Sabkha Brines, evaporite crystallization and microbial activity in Al-Kharrar Sabkha and their implication on future infrastructures in Rabigh Area, Red Sea coastal plain of Saudi Arabia. Environmental Earth Sciences, 2017, 76(10): 1-18. DOI: 10.1007/s12665-017-6686-6.

[28] Valiashko MG eds. Geochemical laws of the formation of potash deposits. Beijing: China Industry Press, 1965: 55-57. [Valiashko MG. 钾盐矿床形成的地球化学规律. 北京: 中国工业出版社, 1965: 55-57.]

[29] Li WX, Zhang XY, Miao WL et al. Hydrochemical characteristics of oilfield waters in Lenghu No.3 structure area of north edge of Qaidam Basin. Journal of Salt Lake Research, 2016, 24(2): 12-18. [李雯霞, 张西营, 苗卫良等. 柴达木盆地 北缘冷湖三号构造油田水水化学特征. 盐湖研究, 2016, 24(2): 12-18.]

[30] Shi GC, Zhang XY, Li YS et al. Hydrochemical components and their distribution characteristics of oilfield waters in No.4 
Structure of Lenghu, Qaidam Basin. Journal of Salt Lake Research, 2016, 24(2): 19-25. [石国成, 张西营, 李永寿等. 柴达木盆地北缘冷湖四号构造油田水水化学组成及其分布特征. 盐湖研究, 2016, 24(2) : 19-25.]

[31] Hay WW, Migdisov A, Balukhovsky AN et al. Evaporites and the salinity of the ocean during the phaneroxoic: implications for climate, ocean circulation and life. Palaeogeogr, Palaeoclimatol, Palaeoecol, 2006, 240: 3-46. DOI: 10.1016/ j.palaeo.2006.03.044.

[32] Zhou X, Li CJ. Hydrogeochemistry of deep formation brines in the central Sichuan Basin, China. Journal of Hydrology, 1992, 138(1) : 1-15. DOI: 10.1016/0022-1694(92) 90152-L.

[33] Yin F. A study of the hydrochemistry of the subsurface brines in the southwestern Sichuan Basin [Dissertation]. Beijing: China University of Geosciences, 2016. [尹菲. 四川盆地西南地区地下卤水水化学研究 [学位论文]. 北京: 中国地质 大学, 2016.]

[34] Fontes JC, Matray JM. Geochemistry and origin of formation brines from the Paris Basin, France: 2. saline solutions associated with oil fields. Chemical Geology, 1993, 109(1/2/3/4) : 149-175. DOI: 10.1016/0009-2541(93)90068-T.

[35] Fan QS, Ma HZ, Tan HB et al. Characteristics and origin of brines in western Qaidam basin. Geochimica, 2007, 36(6) : 601-611. [ 㚞启顺, 马海州, 谭红兵等. 柴达木盆地西部卤水特征及成因探讨. 地球化学, 2007, 36(6): 601-611.]

[36] Lin YT, He JQ, Wang TD et al. Geochemical characteristics of potassium rich brine in middle Triassic Chengdu salt basin of Sichuan Basin and its prospects for brine tapping. Geology of Chemical Minerals, 2002, (2) : 72-84. [林耀庭, 何金 权, 王田丁等. 四川盆地中三叠统成都盐盆富钾卤水地球化学特征及其勘查开发前景研究. 化工矿产地质, 2002, (2) : 72-84.

[37] Han JJ, Zhou X, Jiang CL et al. Hydrochemical characteristics, origin and evolution of the subsurface brines in western Qaidam Basin. Geoscience, 2013, 27(6): 1454-1464. [ 韩佳君, 周训, 姜长龙等. 柴达木盆地西部地下卤水水化学特 征及其起源演化. 现代地质, 2013, 27(6)：1454-1464.] 